\title{
Job Satisfaction of Hotel Employees Conceptual Model Construction and Evaluation
}

\author{
Huan Yuan, Kuang Jiaqing \\ Hotel Management College, Nanjing Institute of Tourism and Hospitality, Nanjing, Jiangsu \\ Email address: \\ yuanhuan1987@yeah.net (Huan Yuan),jqkuang-4709@163.com (Kuang Jiaqing)
}

To cite this article:

Huan Yuan, Kuang Jiaqing. Job Satisfaction of Hotel Employees Conceptual Model Construction and Evaluation. International Journal of Business and Economics Research. Vol. 8, No. 1, 2019, pp. 1-5. doi: 10.11648/j.ijber.20190801.11

Received: November 27, 2018; Accepted: December 25, 2018; Published: January 19, 2019

\begin{abstract}
Job satisfaction of hotel employees means the working environment, material security and career development plan provided by the hotel can meet the satisfaction of many expectations of the hotel employees. The conceptual model of hotel employees job satisfaction constructs a hotel employees job satisfaction evaluation system from five aspects: job content satisfaction, job environment satisfaction, job return satisfaction, management status satisfaction and career development satisfaction, and constructs the hotel employees job satisfaction evaluation model based on the matter-element mode.
\end{abstract}

Keywords: Hotel Employees, Job Satisfaction, Conceptual Model, Index System, Matter-Element Mode

\section{Introduction}

In recent years, with the improvements of people's living standards, people's pursuit of life is not limited to food and clothing in the traditional sense. According to Maslow's hierarchical theory of demand, people need to realize their own value on the basis of meeting the most basic material needs. For the hotel industry, as a service industry, the basic industry criterion is to satisfy customers. Customer satisfaction requires the joint efforts of hotel employees. Therefore, for hotels, it is necessary to enhance the enthusiasm of the employees through various means, and then enhance customer satisfaction. Therefore, it is of great significance to explore how to improve job satisfaction of hotel employees.

\section{Definition and Conceptual Model of Hotel Employee Job Satisfaction}

The satisfaction degree of the employee concept was first proposed by Hoppock, a famous American psychologist in 1935, and the concept was measured by Thurston Attitude Scale. Since then, people have carried out many discussions on job satisfaction, and put forward a variety of job satisfaction concepts and scales. Generally speaking, employee satisfaction refers to employees' actual feelings of accepting an enterprise compared with their expectations.
Employee satisfaction itself is a kind of psychological feedback, which is related to two factors: one is the expectation of employees for the jobs, the other is the real feelings of employees. In general, employee expectations for the jobs are closely related to their own conditions, insights, knowledge systems and so on, and remain unchanged within a certain time range. Therefore, employee satisfaction largely depends on the true feelings of employees. These kinds of true feeling are related to the working environment, employees' salary, employee development platform and Employees' welfare. Therefore, for enterprises, to improve employee satisfaction, it is necessary to start from the needs of employees to maximize the survival and development of employee and other requirements.

Based on this, this study considers that hotel employees job satisfaction refers to the working environment, material guarantees and career development planning provided by the hotel for employees (collectively referred to as external conditions), which can meet the satisfaction degree of the expectations of employees for the hotel.

Job satisfaction of hotel employees is a broad category, which involves three aspects: first, the hotel employee external working conditions system; second, the satisfaction evaluation system of the hotel employee external working condition system; third, the improvement system for satisfaction of the hotel employee external working condition system. 
Based on the above analysis, a conceptual model of job satisfaction of hotel employees is constructed, as shown in Figure 1.

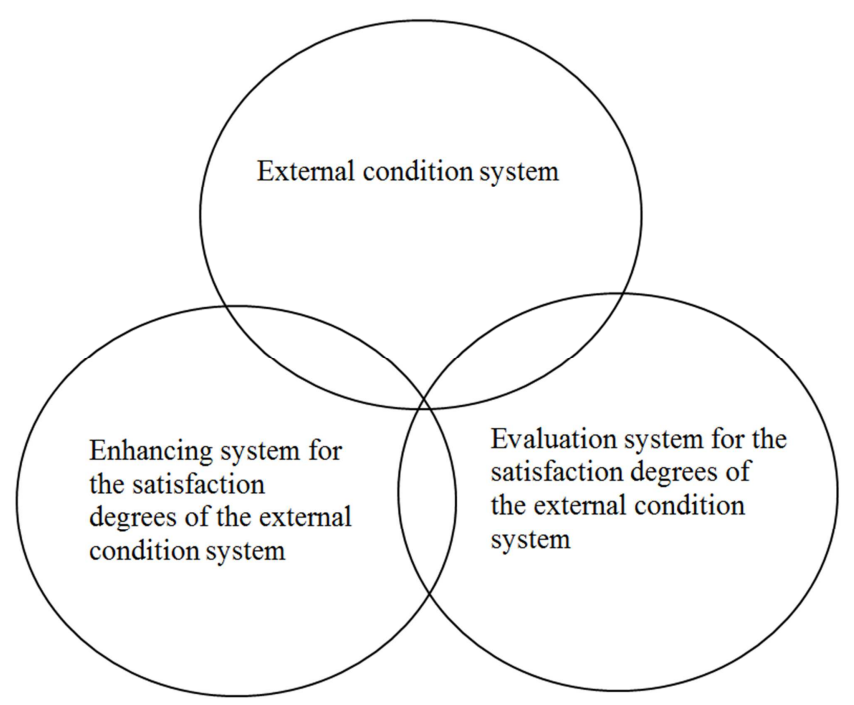

Figure 1. Conceptual model of job satisfaction of hotel employees.

Among the three components of the conceptual model of job satisfaction of hotel employees, the external condition system of hotel employees work refers to a series of external conditions, including working environment, development.

space, career planning, job content and interpersonal relationship, and a series of external conditions the hotel provides for the development of the employees as the service object. The evaluation system for the satisfaction degree of the hotel employee external working conditions refers to the whole set of evaluation system which is constructed for learning about the series of external conditions the hotel provides for the employees, including the index systems, evaluation methods and others which are able to meet the satisfaction degrees of the hotel employees. The enhancing system for the satisfaction degrees of the external condition system refers to the set of the methods the hotel can apply for enhancing the working enthusiasm of the hotel employees to raise the satisfaction degrees of the external working condition system of the hotel employees.

\section{Construction of the Evaluation System for the Job Satisfaction of Hotel Employees}

In order to effectively understand the job satisfaction of hotel employees and provide reference information for improving the external conditions of hotel employees, it is necessary to understand the job satisfaction of hotel employees. This involves the construction of the evaluation system for the job satisfaction of hotel employees.

\subsection{Construction of the Evaluation Index System for the Job Satisfaction of Hotel Employees}

According to the definition of the concept of job satisfaction of hotel employees, we can see that the external conditions provided by the hotel include working environment, material security and career development planning, etc. Therefore, when building the evaluation index systems of the job satisfaction of hotel employees, we should carry out the constructions base on the scientific, systematic, comparable and operable principles.

Through the investigation of hotel employees and the reading of the existing literature, the evaluation index system of job satisfaction of hotel employees is formed, as shown in Table 1.

Table 1. Evaluation index system for job satisfaction of hotel employees.

\begin{tabular}{|c|c|c|}
\hline Target layer & First level index & Two level index \\
\hline \multirow{18}{*}{$\begin{array}{l}\text { Hotel employees work } \\
\text { satisfaction } \\
\text { evaluation }(\mathrm{O})\end{array}$} & \multirow{4}{*}{ Job satisfaction $\mathrm{X} 1$} & Workload satisfaction $\mathrm{X}_{11}$ \\
\hline & & Job training satisfaction $\mathrm{X}_{12}$ \\
\hline & & Personal skills and ability development satisfaction $\mathrm{X}_{13}$ \\
\hline & & Job intensity satisfaction $\mathrm{X}_{14}$ \\
\hline & \multirow{2}{*}{ Work environment satisfaction $\mathrm{X}_{2}$} & Satisfaction of working space conditions $\mathrm{X}_{21}$ \\
\hline & & Satisfaction of life supporting conditions $\mathrm{X}_{22}$ \\
\hline & \multirow{5}{*}{ Job reward satisfaction $X_{3}$} & Salary satisfaction $\mathrm{X}_{31}$ \\
\hline & & Welfare system satisfaction $\mathrm{X}_{32}$ \\
\hline & & Vacation system satisfaction $\mathrm{X}_{33}$ \\
\hline & & Bonus system satisfaction $\mathrm{X}_{34}$ \\
\hline & & Return fairness satisfaction $\mathrm{X}_{35}$ \\
\hline & \multirow{4}{*}{ Management status satisfaction $\mathrm{X}_{4}$} & Employees satisfaction degree $\mathrm{X}_{41}$ \\
\hline & & Satisfaction of assessment system $\mathrm{X}_{42}$ \\
\hline & & Reward and punishment system satisfaction $\mathrm{X}_{43}$ \\
\hline & & Management satisfaction $\mathrm{X}_{44}$ \\
\hline & \multirow[t]{3}{*}{ Career development satisfaction $\mathrm{X}_{5}$} & Personal promotion opportunity satisfaction $\mathrm{X}_{51}$ \\
\hline & & Hotel development satisfaction $\mathrm{X}_{52}$ \\
\hline & & Industry development satisfaction $\mathrm{X}_{53}$ \\
\hline
\end{tabular}


From Table 1, we can see that five aspects can reflect the job satisfaction of hotel employees: job content satisfaction, job environment satisfaction, job return satisfaction, management status satisfaction and career development satisfaction. Furthermore, according to the above five aspects, we can adopt several specific indicators to reflect respectively.

\subsection{Construction of the Evaluation Model of the Job Satisfaction for Hotel Employees}

Considering the complexity of the job satisfaction index system of hotel employees, it involves two levels of indicators, and the number of first-level indicators is 5 , and the number of second-level indicators is 18 . Therefore, in order to fully understand the job satisfaction of hotel employees, it is necessary to establish a comprehensive method to deal with multi-level and multi-index. Based on this, this study attempts to use matter-element model to discuss the evaluation of the job satisfaction of hotel employees

$$
\begin{aligned}
& R_{01}=\left[\begin{array}{ccc} 
& x_{11} & 0-20 \\
1 L & \mathrm{x}_{12} & 0-20 \\
& x_{13} & 0-20 \\
& x_{14} & 0-20
\end{array}\right], R_{02}=[2 L \\
& R_{014}=\left[\begin{array}{lll} 
& x_{11} & 60-80 \\
4 L & x_{12} & 60-80 \\
& x_{13} & 60-80 \\
& x_{14} & 60-80
\end{array}\right], R_{05}=\left[\begin{array}{ccc} 
& x_{11} & 80-100 \\
5 L & x_{12} & 80-100 \\
& x_{13} & 80-100 \\
& x_{14} & 80-100
\end{array}\right]
\end{aligned}
$$

Section

$$
R_{p 1}=\left[\begin{array}{c}
\text { (Job Content } \\
\text { Satisf action) })
\end{array}\right], \text { to } R_{P 1}=\left[\begin{array}{cc}
x_{11} & 0-100 \\
\mathrm{x}_{12} & 0-100 \\
x_{13} & 0-100 \\
x_{14} & 0-100
\end{array}\right]
$$

In the rest of the indicators, the classical domains and the section fields of different grades are deduced like that.

\subsubsection{Determine the Weights of Evaluation Indicators $X_{i}$ and $U_{\text {is }}$}

This research chooses analytic hierarchy process (AHP) to determine the weight allocation of the index, and assigns the weight of the first-level evaluation index $X_{i}$ to be: $a_{i}$ $(i=1,2, \ldots, 5)$,first order index weight vector $\mathrm{A}=\left(\mathrm{a}_{1}, \mathrm{a}_{2}, \ldots, \mathrm{a}_{5}\right)$, and meets the requirement of $\mathrm{a}_{\mathrm{i}} \geq 0$, and $\sum_{i=1}^{5} a_{i}=1$; Set the weight allocation of the two level evaluation index $U_{\text {is }}$ to be $a_{\text {is }}\left(i=1,2, \ldots, 5 ; s=1,2, \ldots, n_{i}\right)$, the two level index weight vectors $\mathrm{A}_{\mathrm{i}}=\left(\mathrm{a}_{\mathrm{i} 1}, \mathrm{a}_{2}, \ldots, \mathrm{a}_{\mathrm{in}}\right)$, and meets the requirement of $\mathrm{a}_{\mathrm{is}} \geq 0, \sum_{s=1}^{n_{i}} a_{i s}=1$ 。

\subsubsection{Determine the Matter Element to Be Evaluated}

According to the evaluation index system of the job satisfaction of hotel employees, the staff of hotel departments concerned designed the form of questionnaire and distributed it to the hotel staff. The hotel staff surveyed scored each index according to the above-mentioned index system and evaluation criteria, and scored all the hotel staff surveyed. The average value is the $u_{\text {in }}$ value of each index. According to the
Based on matter-element model, the steps of establishing job satisfaction of the evaluation model of hotel employees are as follows:

\subsubsection{Determine the Classical Domains and the Section Fields}

This paper holds that the job satisfaction of hotel employees can be divided into five levels: high, relatively high, general, low and very low. Therefore, each evaluation index of job satisfaction of hotel employee can be divided into five levels from low to high: first, second, third, fourth and fifth. The first-level representatives are very low, the second-level representatives are low, the third-level representatives are general, the fourth-level representatives are high, and the fifth-level representatives are high.

Under the job satisfaction index $\left(X_{1}\right)$, the classical domain $R_{0 j}$ of each level is:

$\left.\begin{array}{ll}x_{11} & 20-40 \\ \mathrm{x}_{12} & 20-40 \\ x_{13} & 20-40 \\ x_{14} & 20-40\end{array}\right], R_{03}=\left[\begin{array}{lll} & x_{11} & 40-60 \\ 3 L & \mathrm{x}_{12} & 40-60 \\ & x_{13} & 40-60 \\ & x_{14} & 40-60\end{array}\right]$

index system, the element number to be evaluated $\mathrm{m}$ for the hotel staff satisfaction evaluation is 6 . Set the subject to be evaluated to be $\mathrm{P}_{\mathrm{m}}(\mathrm{m}=0,1, \ldots, 5)$, the separate calculation result is expressed using matter-element $R_{m}$, called matter-element to be evaluated. Then the matter-elements to be evaluated for the job satisfaction of hotel employees are as follows;

$$
\begin{aligned}
& R_{1}=\left[\begin{array}{ccc} 
& X_{11} & x_{11} \\
P_{1} & X_{12} & x_{12} \\
& X_{13} & x_{13} \\
& X_{14} & x_{14}
\end{array}\right], \quad R_{2=}\left[\begin{array}{lll}
P_{2} & X_{21} & x_{21} \\
X_{22} & x_{22}
\end{array}\right], \\
& R_{3}=\left[\begin{array}{lll} 
& X_{31} & x_{31} \\
P_{3} & X_{33} & x_{32} \\
& X_{34} & x_{34} \\
& X_{35} & x_{35}
\end{array}\right] \\
& R_{4}=\left[\begin{array}{lll} 
& X_{41} & x_{41} \\
P_{4} & X_{42} & X_{42} \\
& X_{43} & x_{43} \\
& X_{44} & x_{44}
\end{array}\right], \quad R_{5=}\left[\begin{array}{rrr} 
& X_{51} & x_{51} \\
P_{5} & X_{52} & X_{52} \\
& X_{53} & x_{53}
\end{array}\right], \\
& R_{0}=\left[\begin{array}{ccc} 
& X_{1} & x_{1} \\
X_{2} & x_{2} \\
P_{0} & X_{3} & x_{3} \\
& X_{4} & x_{4} \\
& X_{5} & x_{5}
\end{array}\right]
\end{aligned}
$$

Among this, $R_{0}$ is the evaluation matter-element of the job satisfaction of hotel employees; $R_{1}$ is the evaluation matter-element of evaluating content satisfaction of $\mathrm{z} ; R_{2}$ is the evaluation matter-element of evaluating the workplace environment satisfaction; $R_{3}$ is the evaluation matter-element of evaluating the work repayment satisfaction; $R_{4}$ is the evaluation matter-element of evaluating the management state; 
$R_{5}$ is the evaluation matter-element of evaluating the vocational development satisfaction; $X_{i}(\mathrm{i}=1,2, \ldots, 5)$ is the weighted value of criteria level indicators.

\subsubsection{Determine the Correlation Degree of Each Index of the Items to be Evaluated on All Levels of J} Set:

$$
K_{j}\left(x_{i}\right)=\left\{\begin{array}{c}
\frac{p\left(x_{i}, x_{0 j i}\right)}{p\left(x_{i}, x_{p i}\right)-p\left(x_{i}, x_{o j i}\right)}, \text { when } \mathrm{p}\left(x_{i}, x_{p i}\right)-\mathrm{p}\left(x_{i}, x_{o j i}\right) \neq 0 \\
-p\left(x_{i}, x_{o j i}\right)-1, \text { when } \mathrm{p}\left(x_{i}, x_{p i}\right)-\mathrm{p}\left(x_{i}, x_{o j i}\right)=0
\end{array}\right.
$$

Which

$$
p\left(x_{i}, x_{0 j i}\right)=\left|x_{i}-\frac{1}{2}\left(a_{o j i}+b_{0 j i}\right)\right|-\frac{1}{2}\left(b_{0 j i}-a_{o j i}\right)
$$

Set

$$
p\left(x_{i}, x_{p i}\right)=\left|x_{i}-\frac{1}{2}\left(a_{p i}+b_{p i}\right)\right|-\frac{1}{2}\left(b_{p i}-a_{p i}\right)
$$

Besides, $\rho\left(\mathrm{x}_{\mathrm{i}}, \mathrm{x}_{0 \mathrm{ji}}\right)$ is the distance between point $\mathrm{x}_{\mathrm{i}}$ and section $\mathrm{x}_{0 \mathrm{j}}$, and $\rho\left(\mathrm{x}_{\mathrm{i}}, \mathrm{x}_{\mathrm{pi}}\right)$ is the distance between point $\mathrm{x}_{\mathrm{i}}$ and section $\mathrm{x}_{\mathrm{pi}}$.

\subsubsection{Calculate the Correlation Degree of the $P_{m}$ to Be Evaluated on All Levels of $J$}

If the weight coefficient of index $X_{i}$ is $a_{i}$, and $\sum_{i=1}^{n} a_{i}=1$, then:

$$
K_{j(p)}=\sum_{i=1}^{n} a_{i} K_{j}\left(x_{i}\right)
$$

Among them, $K_{j(p)}$ is the combination value of the correlation degree of each index of the thing to be evaluated with the weight of the index taken into account. This model is not only the correlation degree calculation model of each evaluation module about grade $\mathrm{j}$, but also the correlation degree calculation model of the whole thing to be evaluated about grade $\mathrm{j}$.

\subsubsection{Grade Assessment}

If $K_{j o}(\mathrm{P})=\max _{j \in(1,2, \ldots, \mathrm{m})} K_{j}(p)$, then $P_{m}$ is classified as grade $j_{0}$.It can be seen that this method can not only make an overall evaluation of hotel staff job satisfaction as a whole, but also analyze the job satisfaction of hotel staff from a macro perspective. It can also manage the job content satisfaction, job environment satisfaction, job return satisfaction and management of hotel staff job satisfaction. The five aspects of satisfaction with the status quo and career development are all reflected, which is conducive to the hotel management to understand the status of hotel staff, and to make suggestions for the hotel staff to improve their working environment.

\section{Conclusion}

Hotel staff is the most direct carrier of hotel operating performance. Therefore, understanding the job satisfaction of hotel employees is conducive to carrying out targeted management measures to ensure that employees have the best working environment and attitude. As the job satisfaction of Hotel employees is reflected in many dimensions, it is necessary to build a more comprehensive evaluation system of the job satisfaction of hotel employees. The efforts made in this study are of great significance to improve the level of hotel management and job satisfaction of hotel staff.

\section{Foundation Project}

Jiangsu Provincial University Philosophy and Social Science Fund Project (2011SJD630028).

\section{References}

[1] LI Guang-hong, HUANG Jun-tao, Cao Dong-qin. Empirical Research on Hotel Employee Satisfaction abroad and Its Enlightenment--Based on the Survey of Siem Reap Sokha Resort in Cambodia [J]. Editor's Highlights, 2018, 11 (4): 93-97.

[2] SUN Hua-di . Study on Influencing Factors of Hotel Employee Satisfaction and Resignation Intention [J]. Hospitality Management Studies, 2018 (3): 83-85

[3] Ouyang, Z, M., Sang, J. Y., Li, P., Peng , J. X.. Organizational Justice and Job Insecurity as Mediators of the Effect of Emotional Intelligence on Job Satisfaction: A Study from China. Personality and Individual Differences, 2015, 76 (76): 147-152

[4] WEN Ji, HOU Pingping .Emotion Intelligence and Job Satisfaction of Hotel Front-line Staff: A Study Based on the Dual-stage Moderating Role of Perceived Organizational Support [J]. Nankai Business Review, 2018, (1): 146-158.

[5] Wang, M., Liao, H., Zhan, Y.. Daily Customer Mistreatment and Employee Sabotage against Customers: Examining Emotion and Resource Perspectives .Academy of Management Journal, 2015, $54(2): 312-334$

[6] Lee, J. H., ok, C. M.. Understanding Hotel Employees' Service Sabotage: Emotional Labor Perspective Based on Conservation of Resource Theory. International Journal of Hospitality Management, 2014, (36):176-187.

[7] HUAng Qian, XIE Chaowu, The Effect of Interaction Between Hotel Employees and Customers on Employees' Work Efficiency and Customer Satisfaction [J]. Tourism Tribune, 2017, 4 (32): 66-77.

[8] Zhang Haoyu, Wang Hui, Guo Li, et, al. Leadership power sharing organization self-esteem and employee job performance: The moderating effect of insider identity perception [J]. Economic Sciences, 2016, (2): 118-128.

[9] CAI jiaqin. Analysis of Influencing Factors of Employee Turnover in Hotel Industry [J]. China Management Informationization, 2018, 4 (21): 91-92.

[10] Zhang Kaili, Tang Ningyu .Being Honest in Organizations: The Antecedents and Outcomes of Employees' Error Admission [J]. Nankai Business Review, 2016, 19 (6): 36-48. 
Biography

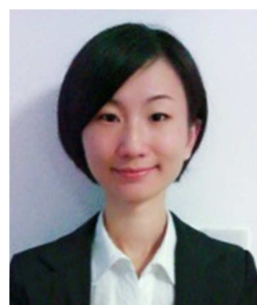

Huan Yuan (1987-), Female, Nanchang Jiangxi Province, lecturer, mainly engaged in catering management research.

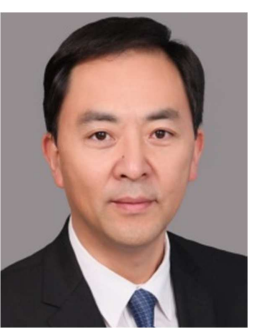

Kuang Jiaqing (1963-), male, Taixing, Jiangsu Province, dean, associate professor, mainly engaged in hotel management research. 